\title{
Assessment of the masking effects of birdsong on the road traffic noise environment
}

Yiying Hao, Jian Kang, and Heinrich Wörtche

Citation: The Journal of the Acoustical Society of America 140, 978 (2016); doi: 10.1121/1.4960570

View online: https://doi.org/10.1121/1.4960570

View Table of Contents: http://asa.scitation.org/toc/jas/140/2

Published by the Acoustical Society of America

\section{Articles you may be interested in}

Perceptual assessment of quality of urban soundscapes with combined noise sources and water sounds The Journal of the Acoustical Society of America 127, 1357 (2010); 10.1121/1.3298437

Acoustical and perceptual assessment of water sounds and their use over road traffic noise The Journal of the Acoustical Society of America 133, 227 (2013); 10.1121/1.4770242

Acoustical characteristics of water sounds for soundscape enhancement in urban open spaces The Journal of the Acoustical Society of America 131, 2101 (2012); 10.1121/1.3681938

Effects of natural sounds on the perception of road traffic noise

The Journal of the Acoustical Society of America 129, EL148 (2011); 10.1121/1.3567073

Similarity and pleasantness assessments of water-fountain sounds recorded in urban public spaces The Journal of the Acoustical Society of America 138, 3043 (2015); 10.1121/1.4934956

Audio-visual interaction and perceptual assessment of water features used over road traffic noise The Journal of the Acoustical Society of America 136, 2609 (2014); 10.1121/1.4897313 


\title{
Assessment of the masking effects of birdsong on the road traffic noise environment
}

\author{
Yiying Hao and Jian Kanga) \\ School of Architecture, University of Sheffield, Western Bank, Sheffield S10 2TN, United Kingdom \\ Heinrich Wörtche \\ INCAS ${ }^{3}$, Assen, Dr. Nassaulaan 9, 9401 HJ Assen, the Netherlands
}

(Received 20 August 2014; revised 7 May 2016; accepted 14 July 2016; published online 12 August 2016)

This study aims to explore how the soundscape quality of traffic noise environments can be improved by the masking effects of birdsong in terms of four soundscape characteristics, i.e., perceived loudness, naturalness, annoyance and pleasantness. Four factors that may influence the masking effects of birdsong (i.e., distance of the receiver from a sound source, loudness of masker, occurrence frequencies of masker, and visibility of sound sources) were examined by listening tests. The results show that the masking effects are more significant in the road traffic noise environments with lower sound levels (e.g., $<52.5 \mathrm{dBA}$ ), or of distance from traffic (e.g., $>19 \mathrm{~m}$ ). Adding birdsong can indeed increase the naturalness and pleasantness of the traffic noise environment at different distances of the receiver from a road. Naturalness, annoyance, and pleasantness, but not perceived loudness, can be altered by increasing the birdsong loudness (i.e., from 37.5 to $52.5 \mathrm{dBA}$ in this study). The pleasantness of traffic noise environments increases significantly from 2.7 to 6.7 , when the occurrence of birdsong over a period of $30 \mathrm{~s}$ is increased from 2 to 6 times. The visibility of the sound source also influences the masking effects, but its effect is not as significant as the effects of the three other factors. (C) 2016 Acoustical Society of America.

[http://dx.doi.org/10.1121/1.4960570]

$[\mathrm{BSF}]$

Pages: $978-987$

\section{INTRODUCTION}

With the emergence of the concept of soundscape, which is defined as an "acoustic environment as perceived or experienced and/or understood by people, in context" by ISO/TC 43/SC 1, the scope of research on urban sound environments has been extended from traditional noise control to multi-disciplinary research. ${ }^{1-6}$ Beyond the total sound level of a sound environment, the significance of sound meaning has also been emphasised. ${ }^{7,8}$ The identification and taxonomy of multiple sound events in the soundscape of daily life have become essential in soundscape studies. Natural sounds, such as birdsong and water sounds, which may benefit people's relaxation in urbanised areas, ${ }^{9}$ have been studied frequently, with particular considerations for their interaction with common urban noise, e.g., road traffic noise. ${ }^{10-13}$ As a result, the concept of "masking" has re-emerged within the scope of soundscape because masking effects have been demonstrated to have considerable effects on the quality of soundscape. ${ }^{6,14,15}$ Furthermore, due to the crucial role of human visual-aural interaction in sound environment assessments, integrated studies of soundscape and landscape have also been conducted recently. ${ }^{16-19}$

Great attention has long been paid to research on auditory masking, but the scope of masking is mainly limited to the domains of acoustics and psychoacoustics. Although early studies of masking were mainly developed based on experiments using pure tones, ${ }^{20}$ the definition and understanding of masking

a)Electronic mail: j.kang@sheffield.ac.uk have recently become rather diverse. Masking is defined from the viewpoint of both the acoustic properties of sound and human hearing. ${ }^{21-26}$ Among the definitions, two main categories of masking, namely, "energetic masking" and "informational masking", have been widely accepted and investigated. ${ }^{27-30}$

However, in real-life soundscapes, the roles of sound source perception and cognition are highly relevant to masking effects. ${ }^{31}$ Thus, it is essential to study masking in soundscapes with commonly recognised sound sources in daily life (e.g., traffic noise and bird chirping). It has also been observed that the masking capability of natural sounds is lower than that predicted by the model of energetic masking of Moore et al..$^{32,33}$ Context plays a vital role in determining masking effects; ${ }^{32}$ hence, informational masking that considers the effects of different contexts ${ }^{28}$ should be an important concern in soundscape studies, in addition to energetic masking. Indeed, masking is explained as a hearing phenomenon through which soundscape characteristics are altered by the presence of interfering sound event(s) in specific contexts. The contexts are derived from real-life sound environments, such as the variable distances between receivers and sound sources as a result of urban planning, ${ }^{4,34}$ different occurrence frequencies of sound events (e.g., bird chirping varying by time of day and bird density ${ }^{35-37}$ ), and direct visibility of sound sources.

This study therefore aims to explore how four key factors, namely, the distance of the receiver from a sound source, the loudness of the masker, the occurrence frequencies of the masker, and the visibility of the sound sources, 
may affect the masking effects of birdsong on road traffic noise, which was accomplished by carrying out a series of listening tests. Two common sounds, road traffic noise and birdsong, were selected as the target and masker, respectively, because they have considerable interactions in urbanised areas ${ }^{38}$ and because birdsong has been demonstrated to be the most preferred natural sound in the traffic noise environment. ${ }^{14,17}$

\section{METHODOLOGY}

Based on the analysis of recordings of typical real sound environments dominated by road traffic noise and birdsong, listening tests were designed using a series of reproduced acoustic stimuli.

\section{A. Sound recordings}

To reproduce acoustic stimuli and investigate the characteristics of the urban road traffic noise environment, sound recordings were collected along two typical main roads in urban areas, namely, Crookes Valley $\operatorname{Road}(2 \times 1$ lane, $50 \mathrm{~km} / \mathrm{h})$, Sheffield, UK, and Hoofdlaan $(2 \times 1$ lane, $50 \mathrm{~km} / \mathrm{h})$, Assen, the Netherlands, which both lead to the city centres, with trees and hedges flanking the roads. An Edirol R-44 Portable Recorder and Tascam DR-680 digital recorder were used for sound recording. The microphone height was $1.6 \mathrm{~m}$. The sound samples were recorded and stored as 16-bit, 44.1-kHz wave files. To record the spatial road traffic noise distribution, simultaneous multi-channel recordings were collected at distances of 1, 4, 9, 19, and $50 \mathrm{~m}$ from the side of Crookes Valley Road during summer 2013 rush hours. Furthermore, photographs were captured from the locations where the microphones were installed, facing the road, to record the scenes where the sound events occurred. To record the temporal changes in both road traffic noise and birdsong, single-channel sound recordings were performed on a pathway at a distance of $2 \mathrm{~m}$ from the road side of Hoofdlaan during sunny and windless weekdays in September 2013. The recordings started at sunrise (approximately 07.30) and ended at sunset (approximately 19.30), ${ }^{39}$ considering the effect of daytime on bird chirping behaviour. ${ }^{35}$ Six five-minute sound recordings collected each hour over the $12 \mathrm{~h}$ of daytime were ultimately collected.

To obtain the representative sound pressure levels and occurrence frequencies for acoustic stimulus reproduction, an analysis was carried out with 36 5-min sound recordings of traffic noise and birdsong (three recordings for every $12 \mathrm{~h}$ ) at Hoofdlaan. Traffic noise and birdsong were both measured as A-weighted sound pressure level (LAeq). The sounds of car passing that were audible for at least $10 \mathrm{~s}$ were labeled as continuous car passing events. One bird chirping event was annotated when the time spacing was longer than $0.5 \mathrm{~s}$ between a chirping's last peak value (LAeq) and the next chirping's first peak value, and one birdsong event may include one or a series of bird chirps. Figure 1 shows examples of typical annotated events of car passing and birdsong. The time-component matrix chart (TM chart), which is a programme for sound annotation and calculation of time percentage of the sound level range and time percentage of the sound event audible as manually identified and labeled, ${ }^{40,41}$ was employed in this study. The time history of each recording with LAeq values was first generated. Then in the TM chart, the sound events of "car passing" and "bird chirping" were classified by sound annotation of the time history, and then the percentage of their sound level range and percentage of the audible sound events were automatically calculated by the programme. The sound pressure levels were classified into six ranges: 30-40, 40-50, 50-60, 60-70, 70-80, and $>80 \mathrm{dBA}$. Figure 2 shows the percentages of each sound level range of cars passing and birds chirping over the total time history. For cars passing, the sound levels between 50 and $60 \mathrm{dBA}$ occupied the highest proportion, at $51.8 \%$, whereas only a few sound levels were beyond $70 \mathrm{dBA}$, at $0.9 \%$. The ranges of $60-70 \mathrm{dBA}(15.9 \%)$ and $40-50 \mathrm{dBA}(30.7 \%)$ represented the high and low sound level ranges, respectively. For birds chirping, most sound levels $(64.0 \%)$ were in the $40-50 \mathrm{dBA}$ range, followed by the ranges of $30-40 \mathrm{dBA}(26.0 \%)$ and $50-60 \mathrm{dBA}(11 \%)$. Figure 2 shows that, in general, the distribution of sound levels associated with birds chirping was $10 \mathrm{dBA}$ lower than that of sound levels associated with cars passing. The mean A-weighted sound pressure level of backgrounds (excluding cars passing and birds chirping) was calculated to be approximately $36.2 \mathrm{dBA}$. Figure 3 shows the time percentages of audible cars passing and birds chirping over the 12 daytime hours. Table I shows the event frequencies of cars passing and birds chirping. The percentages in Fig. 2 and the data presented in Table I are the mean values of the three recordings over each of the 12-h periods to avoid the effect of rare individual noises. The mean percentage of audible cars passing in Fig. 3 is 55.9\%, which is used as a constant percentage for the period of cars passing in the following acoustic stimulus reproductions. Table I shows that the mean occurrence frequency of cars passing over the $12 \mathrm{~h}$ is 18 in five minutes, which is also used as a constant typical occurrence. Moreover, the variant percentage (11.3-37.7\%) and occurrence frequencies of audible birds chirping between 07:30 and 14:30 (when birds chirping mainly occurred) was the factor examined in the ensuing experiment.

\section{B. Acoustic stimuli}

Four stimuli groups, groups A, B, C, and D, were reproduced to examine the four previously mentioned factors: the distance of the receiver from a road, loudness of masker, occurrence frequencies of masker, and visibility of sound sources, respectively. The acoustic stimuli were constructed based on the recorded audio using Adobe Audition CS6. The length of the acoustic stimuli was confirmed to be $30 \mathrm{~s}$ according to the study on the time scales of participants' constant assessments conducted by Pheasant et al., ${ }^{16}$ although different lengths of acoustic stimuli were used in previous listening experiments on masking and soundscape. ${ }^{14,16,17}$ The audio clips of birds chirping were cut from the single-channel sound recordings at Hoofdlaan when the background noise was lower than $36.2 \mathrm{dBA}$. To make the acoustic stimuli more realistic, multiple patterns of bird 


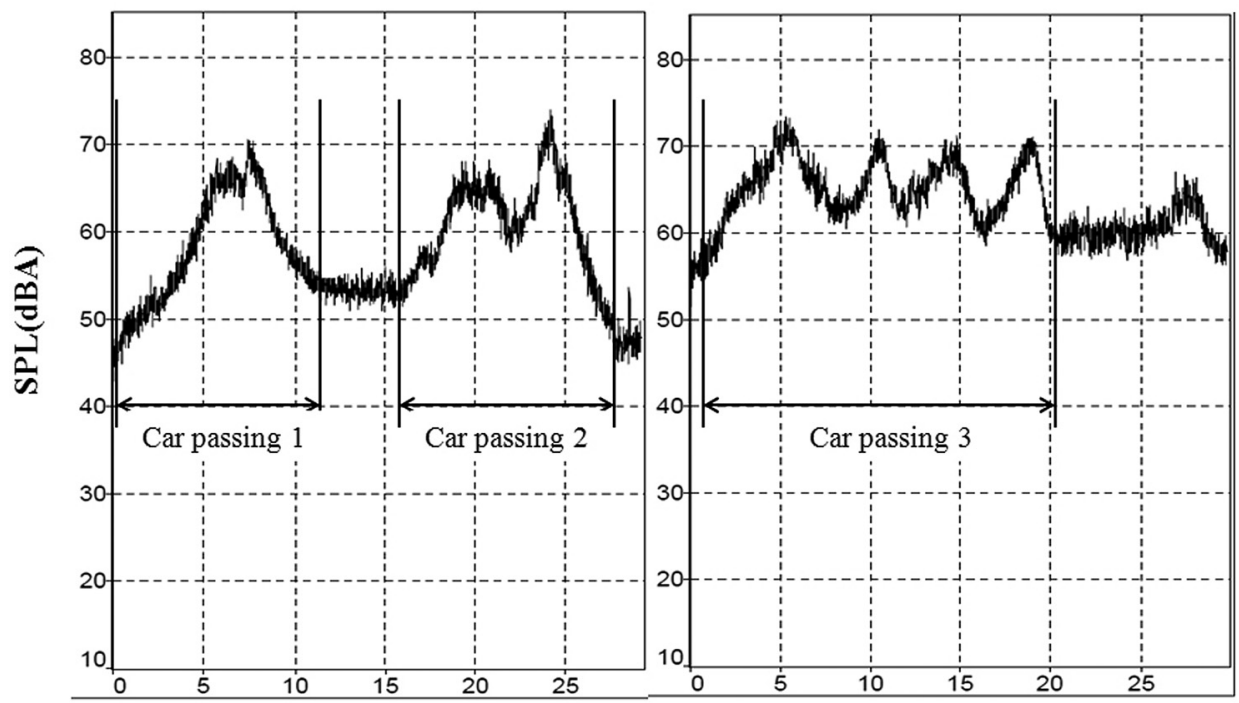

(a)

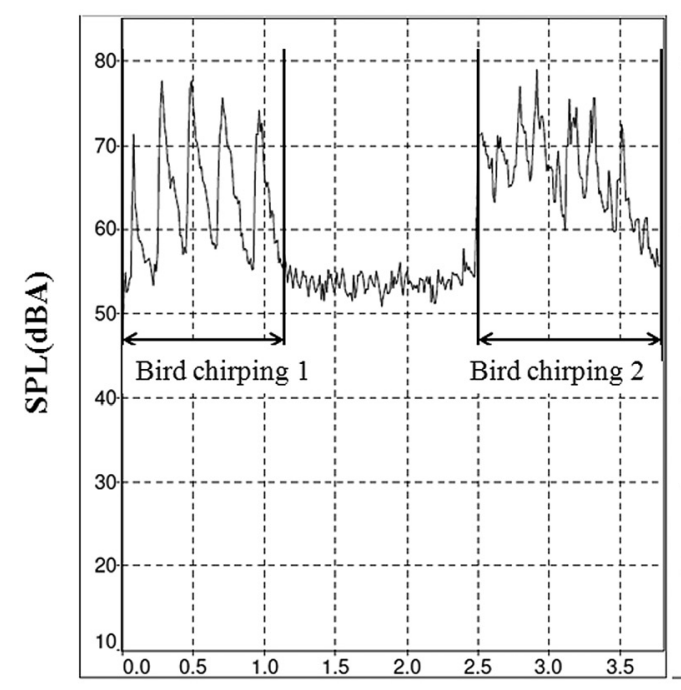

Time(s)

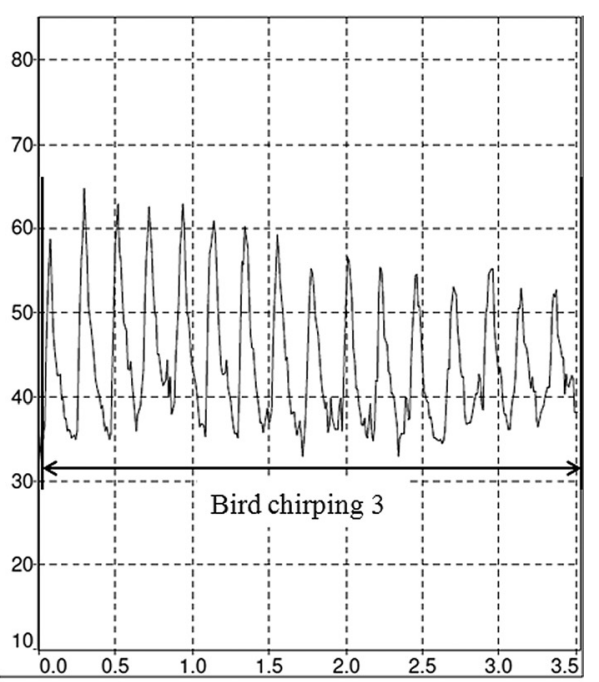

Time(s)

chirping recordings from common urban passerine bird species in Europe ${ }^{42,43}$ were included, e.g., great tit, common blackbird, and sparrow. The frequencies of birds chirping mainly fell within the range $2-10 \mathrm{kHz}$. The audio clips of

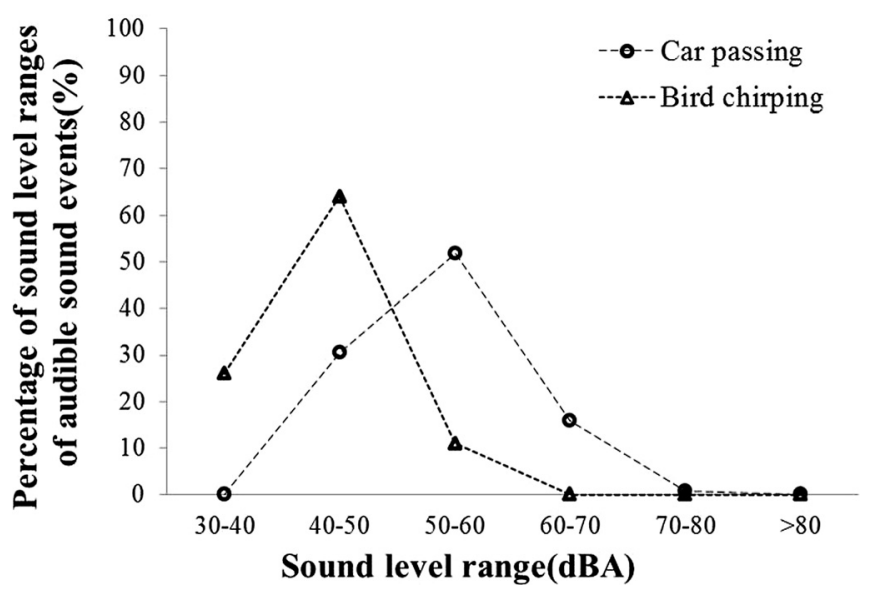

FIG. 2. Time percentage of each sound level range of cars passing over their total time history. $8 \mathrm{~s}$ in each stimulus.
FIG. 1. Examples of annotated sound events of the recordings: (a) car passing; (b) bird chirping. cars passing were cut directly from the recordings captured by the two main roads.

Group A is composed of 10 acoustic stimuli to explore how the distance of the receiver from a road influences the masking effects. Five acoustic stimuli, constituting subgroup I, were the original recordings gathered at distances of 1,4 , 9, 19, and $50 \mathrm{~m}$ from Crookes Valley Road, which remain the different loudness and spectral. The other five acoustic stimuli, constituting subgroup II, were reproduced by adding the same birds chirping at $52.5 \mathrm{dBA}$, which were audible for

Group B, in which 20 acoustic stimuli were included, was formed to investigate how the loudness of the masker influenced the masking effects. Two audio clips of birds chirping ( $8 \mathrm{~s}, 4$ events) at $52.5 \mathrm{dBA}$ (high) and $37.5 \mathrm{dBA}$ (low) were combined with ten audio clips of cars passing at different sound pressure levels of noisy traffic (i.e., 57.5, 60, 62.5, 65, and 67.5 dBA) and quieter traffic (i.e., 42.5, 45, $47.5,50$, and $52.5 \mathrm{dBA}$ ), respectively, where a 2.5-dBA step was used to represent the differences in masking effects within a sound level range of $10 \mathrm{dBA} .^{1,14}$ 


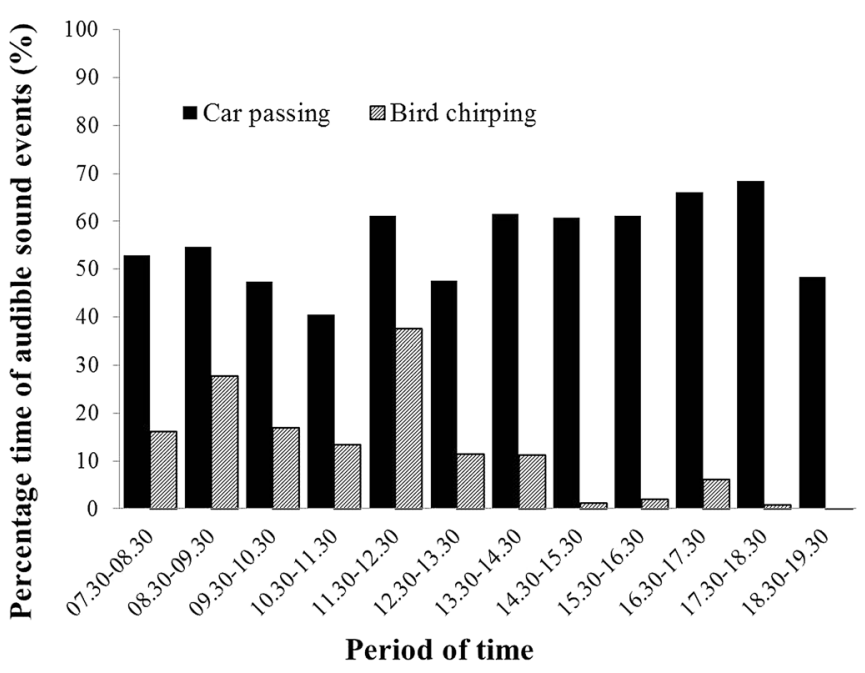

FIG. 3. Time percentage of both cars passing and birds chirping during different daytime periods.

Group $\mathrm{C}$, in which ten acoustic stimuli were included, was formed to elucidate the influence of the occurrence frequency of birds chirping on the masking effects. Five audio clips of different occurrence frequencies of birds chirping, namely, 2, 3, 4, 5, and 6 times (audible for $2 \mathrm{~s}$ each time), were combined with two audio clips of cars passing at 62.5 (high) and $47.5 \mathrm{dBA}$ (low). The occurrence frequency of cars passing was set to a constant value of 2 based on the above-discussed sound analysis.

In group $\mathrm{D}$, the five acoustic stimuli that were used in subgroup II of group A were played back with the pictures captured at the sound recording locations. Ultimately, 45 30$\mathrm{s}$ acoustic stimuli dominated by the sound events of cars passing and birds chirping were reproduced.

Additionally, twenty 30-s acoustic stimuli of daily-life urban sounds at SPLs $<70 \mathrm{dBA}$, including construction, aircraft, human voices, steps, wind rustling leaves and fountains, were added to the stimuli of the four groups in random orders to weaken the subjects' consciousness of the particular purpose of the experiment on traffic noise and birdsong.

\section{Participants and evaluation procedure}

Thirty subjects participated in the experiment, including 12 women and 18 men, aged $18-35$ years. The number of participants was initially determined based on previous related studies $^{17,44}$ and further examined by statistical analysis. The hearing threshold levels of all participants were tested using an audiometer for all frequencies (125, 250, 500, 1000, 2000, $3000,4000,6000$, and $8000 \mathrm{kHz}$ ), and it was found that all participants had normal hearing. A different 30-s audio clip, which was directly cut from one sound recording from Hoofdlaan, was played to the 30 participants to test their capability for sound source recognition. The audio clip included traffic noise, birdsong, dog barking and human voice. All of the participants recognised and indicated that they heard traffic noise and birdsong after listening.

The 65 acoustic stimuli were arranged in a random order and divided into three groups to provide breaks to avoid listener fatigue. The order in which the stimuli were presented to the participants was randomized to minimize order effects. The acoustic stimuli and the pictures were presented through headphones (Sennheiser HD 558) and a projector (Hitachi ED-X33), respectively. The calibration was carried out by using a dummy head (Neumann KU100) before the experiment. The participants were seated in a chair comfortably in an anechoic chamber. The background noise level was approximately 25.0 dBA.

The participants were required to score the sounds after the end of each sound in terms of four adjectives describing the soundscape characteristics, "loud," "natural," "annoying," and "pleasant," on a scale of 0-10, with 0 representing "not at all" and 10 "extremely," based on the basic box diagram from ISO W54. The adjectives have been identified as the characteristics of soundscape quality in previous studies, one of the most commonly used of which is pleasantness. ${ }^{13,14,45}$ For the perceptual assessment of traffic noise, perceived annoyance is an important and frequently examined characteristic. $1,4,46,47$ Considering the significant roles of perceived loudness in the masking study ${ }^{14,32,33}$ and naturalness in human relaxation, ${ }^{9,48-50}$ the two characteristics were also included.

\section{Data analysis}

Normalisation of the responses was conducted according to Eq. (1) prior to the data analysis, as per the previous study, ${ }^{17}$ to reduce the effects of the differences in the ranges of the scores used by the participants in the evaluation,

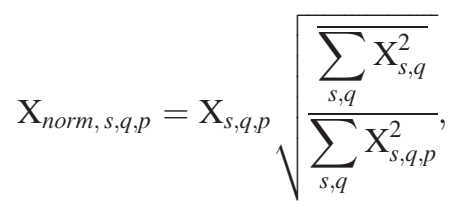

where $s=$ stimuli, $q=$ questions, $\mathrm{X}_{s, q, p}=$ initial answer of the person $p$ for the stimulus $s$ and the question $q$, $\mathrm{X}_{\text {norm }, s, q, p}=$ normalized answer of the person $p$ for the stimulus $s$ and the question $q, \sum_{s, q} \mathrm{X}_{s, q, p}^{2}=$ sum of squares of all the answers for person $p, \overline{\sum_{s, q} \mathrm{X}_{s, q}^{2}}=$ average of the sum of squares for all subjects, and $\overline{\sum_{s, q} \mathrm{X}_{s, q}^{2}}=\sum_{p=1}^{n}(1 / p) \sum_{s, q} \mathrm{X}_{s, q, p}^{2}$.

To test the concordance between the subjects on the evaluation of soundscape, an analysis of two-way mixed intra-class

TABLE I. Frequencies of the sound events of cars passing and birds chirping over $5 \mathrm{~min}$.

\begin{tabular}{lcccccccccccc}
\hline \hline & \multicolumn{1}{c}{ Period of time } \\
\cline { 2 - 11 } & $07: 30$ & $08: 30$ & $09: 30$ & $10: 30$ & $11: 30$ & $12: 30$ & $13: 30$ & $14: 30$ & $15: 30$ & $16: 30$ \\
Sound event & $-08: 30$ & $-09: 30$ & $-10: 30$ & $-11: 30$ & $-12: 30$ & $-13: 30$ & $-14: 30$ & $-15: 30$ & $-16: 30$ & $-17: 30$ & $-18: 30$ & $-19: 30$ \\
\hline Cars passing & 14 & 18 & 13 & 8 & 18 & 13 & 16 & 18 & 20 \\
Birds chirping & 23 & 25 & 30 & 19 & 29 & 25 & 25 & 4 & 6 \\
\hline \hline
\end{tabular}


correlation (ICC) with a 95\% confidence interval was employed. The average intra-class correlation coefficients of perceived loudness, naturalness, annoyance, and pleasantness were $0.969,0.946,0.962$, and 0.872 , respectively, which indicate high agreement in the judgements of the four characteristics and the sufficiency of the number of participants. The high average intra-class correlation coefficients also reflect the reliability of the judgements on the evaluation of soundscape as a result of little order effect. The average intra-class correlation coefficients of pleasantness were lower than those of the three other characteristics, demonstrating that the participants showed a lower degree of consistency when evaluating pleasantness.

A one-way analysis of variance (ANOVA) was conducted to examine the statistically significant mean differences among the acoustic stimuli caused by the four factors (i.e., distance, loudness, occurrence frequency, and visibility) in terms of the scores of the four characteristics. Wilcoxon-signed rank tests were further performed to examine the differences between each pair of acoustic stimuli.

\section{RESULTS}

Table II illustrates all the mean scores of the psychological evaluation of the four soundscape characteristics of the road traffic noise environments.

\section{A. Effects of distance of the receiver from a sound source on masking}

Five acoustic stimuli of traffic noise at distances of 1,4 , 9,19 , and $50 \mathrm{~m}$ from the road (at 69.8, 65.3, 62.3, 56.0, and $47.0 \mathrm{dBA}$ ) with and without birdsong at $52.5 \mathrm{dBA}$ in group A were examined to determine how the distances influenced the masking effects. The one-way ANOVA shows the statistically significant mean differences among the five acoustic stimuli without birdsong in perceived loudness [F (4, $145)=88.99, p=0.000]$, naturalness $[\mathrm{F}(4,145)=19.09$, $p=0.000]$, annoyance $[\mathrm{F}(4,145)=26.51, p=0.000]$, and pleasantness $[\mathrm{F}(4,145)=7.33, p=0.000]$, and five acoustic stimuli with birdsong in perceived loudness $[\mathrm{F}$ (4, $145)=123.07, p=0.000]$, naturalness $[\mathrm{F}(4,145)=61.57$, $p=0.000]$, annoyance $[\mathrm{F}(4,145)=100.04, p=0.000]$, and pleasantness $[\mathrm{F}(4,145)=67.84, p=0.000]$. The results demonstrate that adding birdsong can indeed alter the soundscape characteristics of the road traffic noise environment.

The masking effects significantly increase when the traffic noise fluctuates less and becomes quieter at greater distances. The first row of Table II illustrates the mean values of the four characteristics of the road traffic noise environment at the five distances from the road without and with birdsong at $52.5 \mathrm{dBA}$. The results of the Wilcoxon-signed rank tests reveal that none of the five stimuli have significant

TABLE II. Mean values of the psychological evaluations of the four characteristics. N means audio only; Y means with view.

\begin{tabular}{|c|c|c|c|c|c|c|c|c|c|c|c|c|c|}
\hline \multirow{3}{*}{$\begin{array}{l}\text { Distance of the perceiver } \\
\text { receiver from a sound } \\
\text { source }(\mathrm{m}) \text { (group A) }\end{array}$} & & \multicolumn{3}{|c|}{ Perceived loudness } & \multicolumn{3}{|c|}{ Naturalness } & \multicolumn{3}{|c|}{ Annoyance } & \multicolumn{3}{|c|}{ Pleasantness } \\
\hline & & \multirow[t]{2}{*}{ No birdsong } & \multicolumn{2}{|c|}{$\begin{array}{l}52.5 \mathrm{dBA} \\
\text { birdsong }\end{array}$} & \multirow[t]{2}{*}{ No birdsong } & \multicolumn{2}{|c|}{$\begin{array}{l}52.5 \mathrm{dBA} \\
\text { birdsong }\end{array}$} & \multirow[t]{2}{*}{ No birdsong } & \multicolumn{2}{|c|}{$\begin{array}{l}52.5 \mathrm{dBA} \\
\text { birdsong }\end{array}$} & \multirow[t]{2}{*}{ No birdsong } & \multicolumn{2}{|c|}{$\begin{array}{l}52.5 \mathrm{dBA} \\
\text { birdsong }\end{array}$} \\
\hline & & & $\mathrm{N}$ & $\mathrm{Y}$ & & $\mathrm{N}$ & $\mathrm{Y}$ & & $\mathrm{N}$ & $\mathrm{Y}$ & & $\mathrm{N}$ & $\mathrm{Y}$ \\
\hline & 1 & 9.1 & 8.8 & 8.9 & 0.3 & 1.5 & 1.8 & 8.4 & 8.2 & 7.9 & 0.4 & 0.5 & 0.9 \\
\hline & 4 & 7.7 & 7.4 & 8.2 & 0.3 & 1.9 & 2.1 & 7.3 & 6.9 & 6.8 & 0.7 & 1.0 & 1.6 \\
\hline & 9 & 6.8 & 6.6 & 7.0 & 0.5 & 2.3 & 3.1 & 6.9 & 6.0 & 6.5 & 1.1 & 1.3 & 2.6 \\
\hline & 19 & 5.6 & 5.3 & 5.4 & 0.9 & 4.1 & 4.5 & 5.4 & 4.2 & 4.8 & 1.2 & 2.4 & 4.0 \\
\hline & 50 & 3.6 & 2.4 & 2.7 & 2.4 & 6.3 & 6.5 & 4.1 & 1.7 & 1.8 & 1.9 & 5.5 & 6.7 \\
\hline \multirow[t]{11}{*}{$\begin{array}{l}\text { Traffic noise (dBA) } \\
\text { (group B) }\end{array}$} & & $\begin{array}{l}37.5 \mathrm{dBA} \\
\text { birdsong }\end{array}$ & \multicolumn{2}{|c|}{$\begin{array}{l}52.5 \mathrm{dBA} \\
\text { birdsong }\end{array}$} & $\begin{array}{l}37.5 \mathrm{dBA} \\
\text { birdsong }\end{array}$ & \multicolumn{2}{|c|}{$\begin{array}{l}52.5 \mathrm{dBA} \\
\text { birdsong }\end{array}$} & $\begin{array}{l}37.5 \mathrm{dBA} \\
\text { birdsong }\end{array}$ & \multicolumn{2}{|c|}{$\begin{array}{l}52.5 \mathrm{dBA} \\
\text { birdsong }\end{array}$} & $\begin{array}{l}37.5 \mathrm{dBA} \\
\text { birdsong }\end{array}$ & \multicolumn{2}{|c|}{$\begin{array}{l}52.5 \mathrm{dBA} \\
\text { birdsong }\end{array}$} \\
\hline & 42.5 & 2.6 & \multicolumn{2}{|c|}{2.4} & 6.2 & \multicolumn{2}{|c|}{5.9} & 1.9 & \multicolumn{2}{|c|}{1.9} & 4.3 & \multicolumn{2}{|c|}{5.0} \\
\hline & 45.0 & 3.5 & \multicolumn{2}{|c|}{2.8} & 6.1 & \multicolumn{2}{|c|}{5.9} & 2.3 & \multicolumn{2}{|c|}{2.1} & 5.0 & \multicolumn{2}{|c|}{5.1} \\
\hline & 47.5 & 3.6 & \multicolumn{2}{|c|}{3.0} & 6.0 & \multicolumn{2}{|c|}{6.1} & 2.7 & \multicolumn{2}{|c|}{2.3} & 5.3 & \multicolumn{2}{|c|}{5.6} \\
\hline & 50.0 & 3.9 & & & 5.1 & & & 4.2 & & & 3.9 & & 9 \\
\hline & 52.5 & 4.4 & & & 4.0 & & & 5.2 & & & 2.7 & & 0 \\
\hline & 57.5 & 6.0 & & & 3.7 & & & 4.8 & & & 1.8 & & 1 \\
\hline & 60.0 & 6.7 & & & 3.4 & & & 5.4 & & & 1.5 & & 4 \\
\hline & 62.5 & 7.4 & & & 3.1 & & & 5.6 & & & 1.4 & & 4 \\
\hline & 65.0 & 7.9 & & & 2.9 & & & 6.4 & & & 1.3 & & 1 \\
\hline & 67.5 & 8.1 & & & 2.0 & & & 7.3 & & & 1.2 & & 1 \\
\hline $\begin{array}{l}\text { Occurrence frequencies } \\
\text { of birdsong (group C) }\end{array}$ & & $\begin{array}{c}47.5 \mathrm{dBA} \\
\text { traffic noise }\end{array}$ & $\begin{aligned} & 62 . \\
& \text { traffi }\end{aligned}$ & $\begin{array}{l}\text { BA } \\
\text { loise }\end{array}$ & $\begin{array}{c}47.5 \mathrm{dBA} \\
\text { traffic noise }\end{array}$ & $\begin{aligned} 62.5 \\
\text { traffi }\end{aligned}$ & $\begin{array}{l}\mathrm{BA} \\
\text { loise }\end{array}$ & $\begin{array}{c}47.5 \mathrm{dBA} \\
\text { traffic noise }\end{array}$ & $\begin{array}{r}62.5 \\
\text { traffic }\end{array}$ & $\begin{array}{l}\text { BA } \\
\text { loise }\end{array}$ & $\begin{array}{c}47.5 \mathrm{dBA} \\
\text { traffic noise }\end{array}$ & $\begin{array}{r}62 . \\
\text { traff }\end{array}$ & $\begin{array}{l}\mathrm{dBA} \\
\text { noise }\end{array}$ \\
\hline & 2 & 2.7 & & & 4.7 & & & 2.3 & & & 2.7 & & .5 \\
\hline & 3 & 2.7 & & & 5.1 & & & 2.0 & & & 4.9 & & .5 \\
\hline & 4 & 2.6 & & & 5.8 & & & 2.1 & & & 5.1 & & .6 \\
\hline & 5 & 2.7 & & & 6.2 & & & 1.7 & & & 5.5 & & .2 \\
\hline & 6 & 2.8 & & & 6.4 & & & 1.3 & & & 6.7 & & .4 \\
\hline
\end{tabular}


differences $(p<0.05)$ in perceived loudness when adding birdsong, but all have significant differences in naturalness.

As shown in Table II, the perceived loudness of the traffic noise environment is similar between the with- and without-birdsong conditions, with a maximum mean value difference of 1.2 at $50 \mathrm{~m}$. However, naturalness is largely increased when birdsong is added, especially when the road traffic noise fluctuates less and becomes quieter at 19 and $50 \mathrm{~m}$. For example, with birdsong, naturalness increases by 3.2 at $19 \mathrm{~m}$ and by 3.9 at $50 \mathrm{~m}$ (see Table II). Figure 4 further shows the statistical distribution of the evaluation scores of naturalness with and without birdsong at the five distances, indicating the high agreement in evaluation of naturalness.

For annoyance and pleasantness, the significant differences between the with- and without-birdsong conditions occur only at the distances farther than $19 \mathrm{~m}$. With birdsong, the annoyance of the traffic noise environment decreases by 1 at $19 \mathrm{~m}$ and 2.3 at $50 \mathrm{~m}$, as shown in Table II. Pleasantness can be significantly increased by adding birdsong; for example, at a distance of $50 \mathrm{~m}$, the pleasantness of the traffic noise environment is only 1.9 , whereas it increases to 5.5 when birdsong is mixed (see Table II).

\section{B. Effects of birdsong loudness on masking}

The second row of Table II shows the mean scores of the psychological evaluation of the four soundscape characteristics of the road traffic noise environments with birdsong at 52.5 and $37.5 \mathrm{dBA}$ in group B. Based on the sound analysis of the sound recordings in Sec. II A, the road traffic noise environments are classified into relatively quiet (i.e., 42.5-52.5 dBA) and noisy (i.e., 57.5-67.5 dBA) environments. Table II shows that, in general, the score differences under the two conditions (i.e., birdsong at 52.5 and $37.5 \mathrm{dBA}$ ) become larger with the increase in loudness of traffic noise from $42.5 \mathrm{dBA}$ and then become smaller with the increase in loudness after the sound level reaches $52.5 \mathrm{dBA}$. The effects of masker loudness on

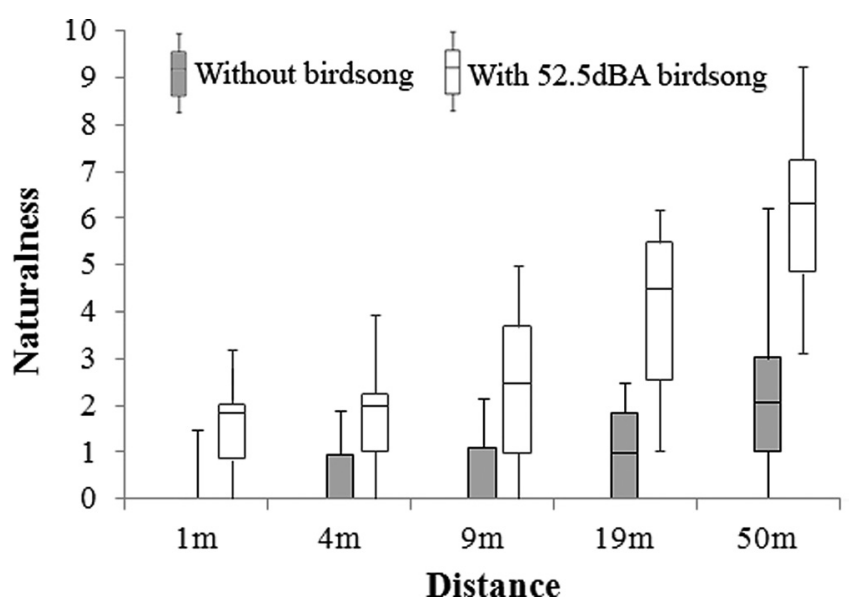

FIG. 4. Box-and-whisker plots of the psychological evaluations of naturalness of the road traffic noise environments at distances of 1, 4, 9, 19, and $50 \mathrm{~m}$ from the road without birdsong and with birdsong at $52.5 \mathrm{dBA}$, showing the statistical distribution of the evaluation scores. masking will be discussed in both quiet and noisy traffic noise environments, respectively.

\section{Quiet traffic noise environment}

To further explore the effects of masker loudness on masking when the noise is relatively quiet, five acoustic stimuli of quiet traffic noise (42.5, 45.0, 47.5, 50.0, and 52.5 dBA) were combined with birdsong at 52.5 and $37.5 \mathrm{dBA}$. The oneway ANOVA shows the significant mean differences among the five acoustic stimuli with $52.5 \mathrm{dBA}$ birdsong only in pleasantness $[\mathrm{F}(4,145)=3.697, p=0.007]$ but not for perceived loudness $[\mathrm{F}(4,145)=1.15, p=0.337]$, naturalness $[\mathrm{F}(4,145)$ $=0.690, p=6.000]$, annoyance $[\mathrm{F}(4,145)=2.11, p=0.082]$, and the significant mean differences among the five acoustic stimuli with $37.5 \mathrm{dBA}$ birdsong in perceived loudness $[\mathrm{F}(4,145)=9.73, p=0.000]$, naturalness $[\mathrm{F}(4,145)=8.69$, $p=0.000]$, annoyance $[\mathrm{F}(4,145)=10.17, p=0.000]$, and pleasantness $[\mathrm{F}(4,145)=13.11, p=0.000]$.

To assess whether significant differences in the masking effects exist between $52.5 \mathrm{dBA}$ birdsong and $37.5 \mathrm{dBA}$ birdsong, Wilcoxon-signed rank tests were conducted. The results reveal that the five acoustic stimuli of quiet traffic noise are not statistically significantly different in perceived loudness $(p>0.05)$, although the mean value differences are not small, 1.0 at $52.5 \mathrm{dBA}$ and 0.6 at $50 \mathrm{dBA}$ (see Table II), which indicates that when the traffic noise is less than 52.5 dBA, louder birdsong does not affect perceived loudness. However, in the Wilcoxon-signed rank tests, the acoustic stimuli of traffic noise at 50.0 and $52.5 \mathrm{dBA}$ are significantly different in naturalness, annoyance, and pleasantness, which indicates that when the traffic noise increases, louder birdsong can effectively improve the soundscape quality.

Figures 5-7 illustrate the statistical distribution of the evaluation scores of naturalness, annoyance, and pleasantness with 37.5 and $52.5 \mathrm{dBA}$ birdsong. As shown in Table II, with 52.5 dBA birdsong, naturalness changes minimally when the traffic noise increases, but with 37.5

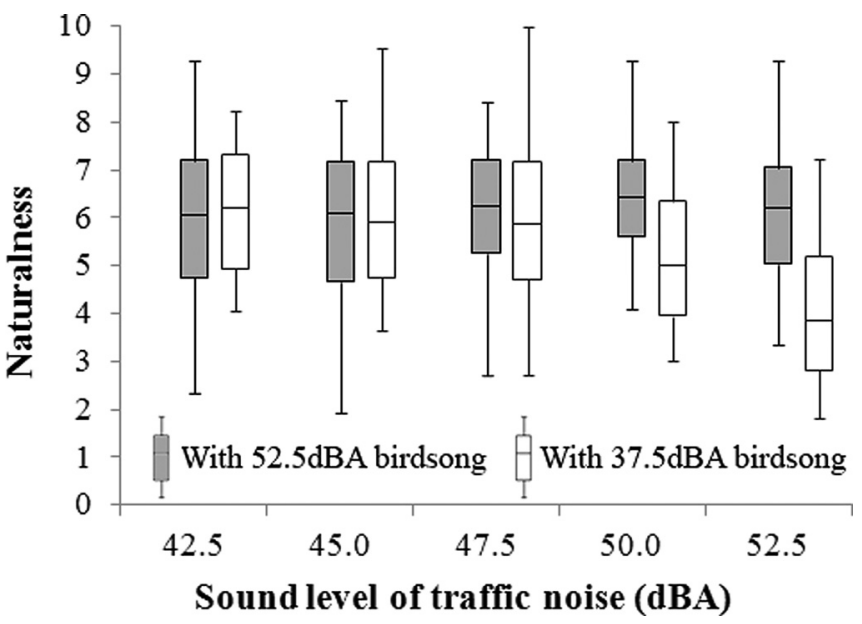

FIG. 5. Box-and-whisker plots of the psychological evaluations of naturalness of the road traffic noise environments at 42.5, 45, 47.5, 50, and 52.5 dBA with 37.5 and $52.5 \mathrm{dBA}$ birdsong, showing the statistical distribution of the evaluation scores. 


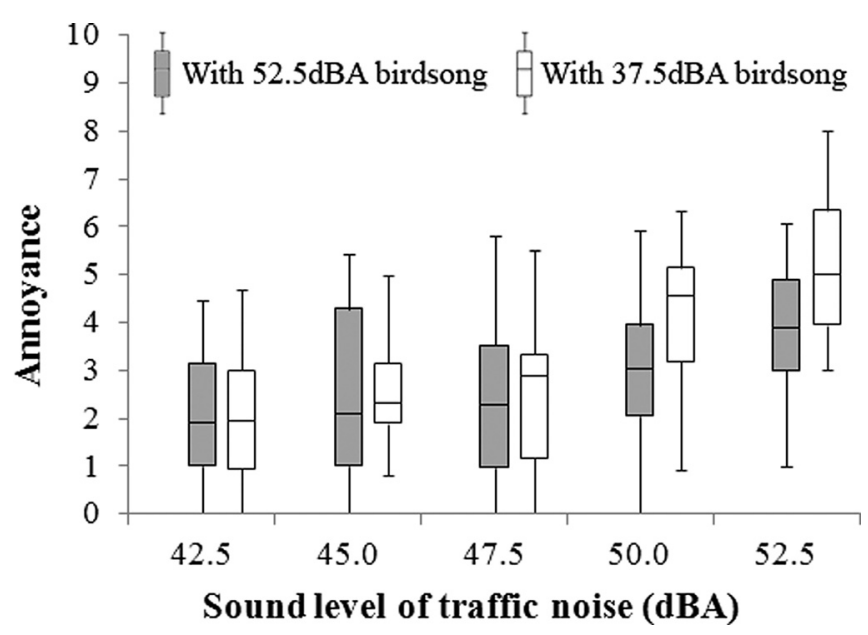

FIG. 6. Box-and-whisker plots of the psychological evaluations of annoyance of the road traffic noise environments at 42.5, 45, 47.5, 50, and 52.5 dBA with 37.5 and $52.5 \mathrm{dBA}$ birdsong, showing the statistical distribution of the evaluation scores.

dBA birdsong, naturalness decreases sharply when the traffic noise is louder than $47.5 \mathrm{dBA}$ (see Fig. 5). Annoyance due to traffic noise is significantly higher with 37.5 dBA birdsong than with $52.5 \mathrm{dBA}$ birdsong when the traffic noise is louder than $50 \mathrm{dBA}$ (see Table II and Fig. 6). For example, the level of annoyance is 5.2 with 37.5 dBA birdsong and 3.9 with $52.5 \mathrm{dBA}$ birdsong when the traffic noise is $52.5 \mathrm{dBA}$ (see Table II). Pleasantness increases slightly and then decreases significantly above $47.5 \mathrm{dBA}$, with either 37.5 or $52.5 \mathrm{dBA}$ birdsong, and it is always higher when birdsong is louder (see Table II and Fig. 7). The increase in pleasantness below $47.5 \mathrm{dBA}$ might be caused by the failure in sound source recognition when the traffic noise is too low.

It appears that birdsong loudness has stronger effects on the evaluation of the four characteristics in the traffic environment at 50.0 and $52.5 \mathrm{dBA}$ than the other sound levels.

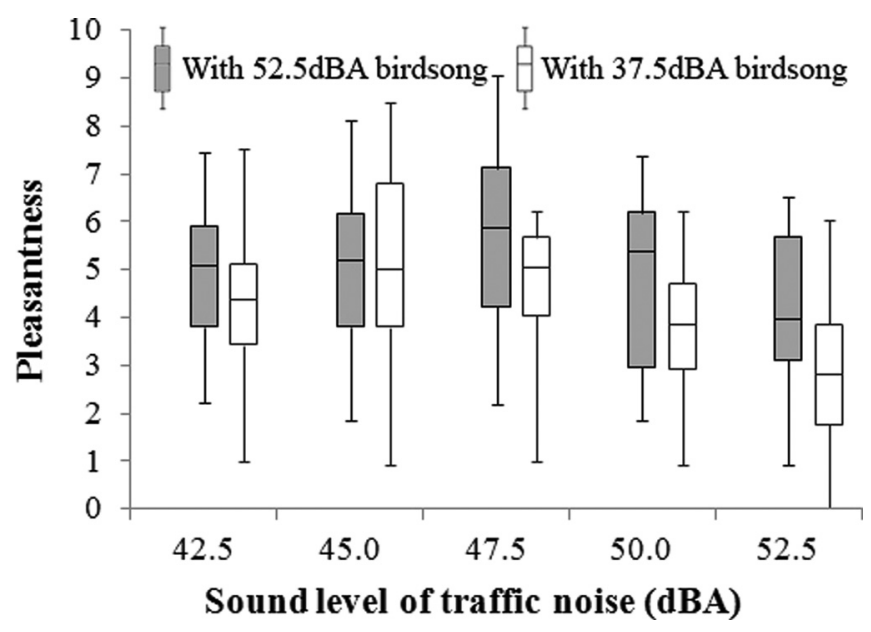

FIG. 7. Box-and-whisker plots of the psychological evaluations of pleasantness of the road traffic noise environments at 42.5, 45, 47.5, 50, and 52.5 dBA with 37.5 and $52.5 \mathrm{dBA}$ birdsong, showing the statistical distribution of the evaluation scores.

\section{Noisy traffic noise environment}

To further explore the effects of masker loudness on masking when the noise is loud, five acoustic stimuli of loud road traffic noise $(57.5,60.0,62.5,65.0$, and $67.5 \mathrm{dBA})$ were combined with birdsong at 52.5 and $37.5 \mathrm{dBA}$. The one-way ANOVA shows the significant mean differences among the five acoustic stimuli with $52.5 \mathrm{dBA}$ birdsong in perceived loudness $[\mathrm{F}(4,145)=16.00, p=0.000]$, naturalness $[\mathrm{F}(4,145)$ $=5.06, p=0.001]$, annoyance $[\mathrm{F}(4,145)=4.88, p=0.001]$, and pleasantness $[\mathrm{F}(4,145)=3.97, p=0.004]$, and five acoustic stimuli with $37.5 \mathrm{dBA}$ birdsong in perceived loudness [F $(4,145)=16.39, p=0.000]$, naturalness $[\mathrm{F}(4,145)=5.05$, $p=0.001]$, annoyance $[\mathrm{F}(4,145)=21.76, p=0.000]$, and pleasantness $[\mathrm{F}(4,145)=9.89, p=0.000]$.

For all four characteristics, the five acoustic stimuli show no significant differences between 52.5 and $37.5 \mathrm{dBA}$ birdsong in the Wilcoxon-signed rank tests. As shown in Table II, the mean values are rather similar between the two sound pressure levels of birdsong, which indicates birdsong loudness has little effect on the masking effects when the traffic noise is louder than $57.5 \mathrm{dBA}$. It is interesting to note that the mean values of annoyance are higher with $52.5 \mathrm{dBA}$ birdsong than with $37.5 \mathrm{dBA}$ when the traffic noise is noisy.

Moreover, to elucidate the relationships between the four characteristics, a two-tailed bivariate analysis and linear regressions between each pair of characteristics were conducted with the mean values reported in Table II. The results show that Annoyance has a significant positive relationship with perceived loudness $\left(p<0.01, \mathrm{R}^{2}=0.904\right)$ and a negative relationship with naturalness $\left(p<0.01, \mathrm{R}^{2}=0.883\right)$. Pleasantness has a significant negative relationship with perceived loudness $\left(p<0.01, \mathrm{R}^{2}=0.905\right)$ and a positive relationship with naturalness $\left(p<0.01, \mathrm{R}^{2}=0.905\right)$.

\section{Effects of occurrence frequencies of birdsong on masking}

The third row of Table II shows the mean psychological evaluation scores of the four soundscape characteristics of the road traffic noise environments with different occurrence frequencies of birdsong, including relatively quiet traffic noise environment (i.e., $47.5 \mathrm{dBA}$ ) and noisy traffic noise environment (i.e., 62.5 dBA). Table II shows that, generally, compared with the quiet traffic noise environment, the occurrence frequencies of birdsong appear to have a weaker influence on the masking effects in the noisy traffic noise environments.

\section{Quiet traffic noise environment}

To study the effects of occurrence frequencies on the masking effects when the noise is relatively quiet, five acoustic stimuli of $42.5 \mathrm{dBA}$ birdsong (2, 3, 4, 5, and 6 repetitions) combined with $47.5 \mathrm{dBA}$ traffic noise in group $\mathrm{C}$ were examined. The one-way ANOVA shows significant differences in the masking effects among the five acoustic stimuli in naturalness $[\mathrm{F}(4,145)=7.17, p=0.000]$, annoyance $[\mathrm{F}(4,145)$ $=2.52, p=0.044]$, and pleasantness $[\mathrm{F}(4,145)=23.36$, $p=0.000]$ but not for perceived loudness $(p=0.587)$, which 
indicates that the occurrence frequency of birdsong indeed influences the masking effects in terms of the soundscape characteristics, excluding perceived loudness.

Table II demonstrates that when the occurrence frequency increases from 2 to 6 repetitions, naturalness increases steadily from 4.7 to 6.4 , annoyance decreases slightly from 2.3 to 1.3 , and pleasantness increases significantly from 2.7 to 6.7. Compared with the naturalness and annoyance, the occurrence frequency of birdsong has a greater effect on pleasantness. It is interesting to note that when the occurrence frequency increases from 2 to 3 , pleasantness increases sharply from 2.7 to 4.9 (see Table II), which could be attributed to the fact that three times the amount of birdsong is necessary to make the birdsong much more noticeable.

\section{Noisy traffic noise environment}

Five acoustic stimuli of birdsong $(2,3,4,5$, and 6 repetitions) combined with noisy traffic noise at $62.5 \mathrm{dBA}$ were also examined. The one-way ANOVA only shows the significant mean differences among the five acoustic stimuli in Pleasantness $[\mathrm{F}(4,145)=2.91, p=0.024]$, but the differences between the occurrence frequencies are small, with a maximum value of 0.9 between 2 and 6 repetitions (see Table II). Therefore, when the traffic noise is noisy, the occurrence frequency of birdsong has little effect on the masking effects. Figure 8 further illustrates the statistical distribution of the evaluation scores of pleasantness with birdsong $(2,3,4,5$, and 6 repetitions) in both quiet and noisy traffic noise environments, showing a significant and highly concordant increase of scores of pleasantness as the sound level of traffic noise decreases from 62.5 to $47.5 \mathrm{dBA}$.

\section{Effects of visibility of sound sources on masking}

To initially investigate the effects of visibility of sound source on masking, five acoustic stimuli of traffic noise and birdsong in group A were played with and without the pictures of in situ scenes. The one-way ANOVA shows significant differences in masking effects among the five stimuli

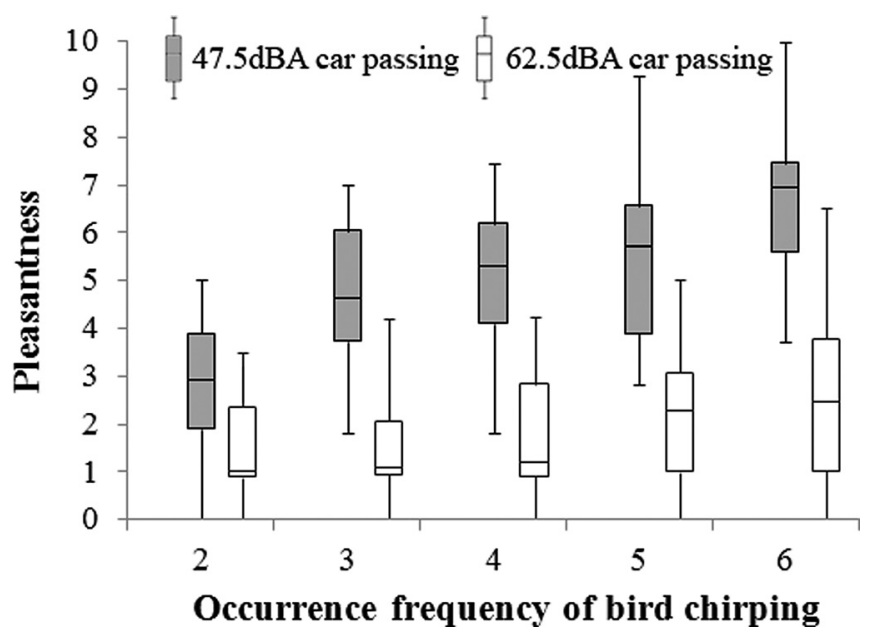

FIG. 8. Box-and-whisker plots of the psychological evaluations of pleasantness of the road traffic noise environments with different occurrence frequencies of birdsong $(2,3,4,5$, and 6 times), showing the statistical distribution of the evaluation scores. with the pictures of in situ scenes in perceived loudness $[\mathrm{F}(4,145)=130.46, p=0.000]$, naturalness $[\mathrm{F}(4,145)$ $=34.54, p=0.000]$, annoyance $[\mathrm{F}(4,145)=64.02, p=0.000]$, and pleasantness $[\mathrm{F}(4,145)=34.07, p=0.000]$. In Wilcoxonsigned rank tests, only pleasantness of the traffic noise at distances of 9, 19, and $50 \mathrm{~m}$ have significant differences between the with- and without-views conditions $(p<0.05)$.

The first row of Table II illustrates the mean values of the four characteristics of the road traffic noise and birdsong environment at distances of 1, 4, 9, 19, and $50 \mathrm{~m}$ with and without the pictures of in situ scenes being played. As shown in Table II, pleasantness showed an increase of 1.3 at a distance of $9 \mathrm{~m}$, an increase of 1.6 at $19 \mathrm{~m}$, and an increase of 1.2 at $50 \mathrm{~m}$ when the in situ scenes were played. Figure 9 further illustrates the statistical distribution of the evaluation scores of pleasantness with and without the in situ scenes.

\section{DISCUSSIONS AND CONCLUSIONS}

This study aimed to explore how four factors, namely, the distance from a sound source, loudness of a masker, occurrence frequencies of a masker, and visibility of sound sources, influence the masking effects of birdsong on the road traffic noise environment using psychological listening experiments. The study first examined the factors that were raised from landscape, urban planning and avian behaviour in real situations. A key finding is that in terms of human auditory, significant informational masking exists between narrow-band (birdsong) and wide-band sounds (traffic noise) with meaning in daily life, and it is significantly influenced by the contextual factors. The results of the study can be used in optimising soundscapes including traffic noise environments.

The masking effects of birdsong on road traffic noise indeed exist in terms of perceived naturalness, annoyance, and pleasantness at different distances of the receiver from a road. When adding birdsong, perceived loudness does not change, but naturalness is largely enhanced. Therefore, birdsong can be considered an important sound marker of naturalness in the urban sound environment. When the receiver

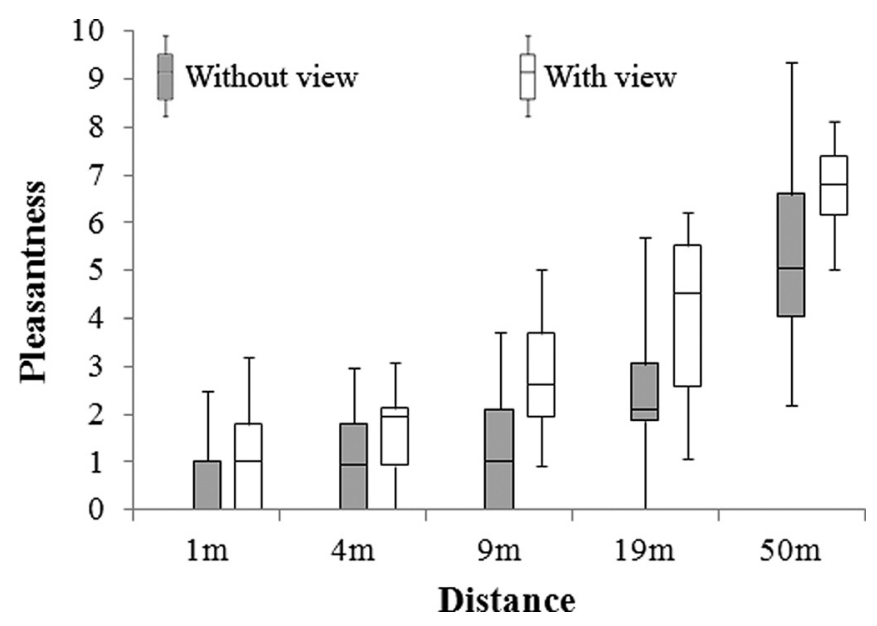

FIG. 9. Box-and-whisker plots of the psychological evaluations of pleasantness of the road traffic noise environments at distances of 1, 4, 9, 19, and $50 \mathrm{~m}$ from the road with and without view of in situ scene, showing the statistical distribution of the evaluation scores. 
is at a certain distance from a road (i.e., farther than $19 \mathrm{~m}$ in this study), annoyance can be significantly reduced and pleasantness increased by adding audible birdsong, therefore, creation of bird habitats is an efficient way to improve the quality of soundscape dominated by traffic noise.

In agreement with the distances from a road, when birdsong loudness increases (i.e., from 37.5 to $52.5 \mathrm{dBA}$ ), the masking effects become more significant in terms of naturalness, annoyance, and pleasantness. It is surprising that when the birdsong is $52.5 \mathrm{dBA}$, the perceived loudness of the quiet traffic noise environment is slightly lower than that when the birdsong is $37.5 \mathrm{dBA}$, although they are not significantly different statistically. This phenomenon may be explained by examining the responses of an interview session after the experiment: when people heard birdsong, they described the sound environment with words as "natural" and "pleasant" rather than "loud," suggesting that naturalness and pleasantness may distract people's attention from loudness. Louder birdsong was evaluated to have higher naturalness and pleasantness, ${ }^{51}$ which may result in less attention on loudness. Irrespective of masker loudness, annoyance due to the traffic noise environment increases and pleasantness decreases sharply when the traffic noise is louder than $47.5 \mathrm{dBA}$. Annoyance increases with an increase in the sound pressure level of birdsong when the traffic noise is loud (higher than $57.5 \mathrm{dBA}$ ). Therefore this data suggests that adding natural masking sounds alone without attenuating traffic noise level is ineffective in improving soundscape quality.

The occurrence frequency of birdsong, similarly to birdsong loudness, influences the masking effects in terms of all soundscape characteristics except for perceived loudness. In relatively quiet traffic noise environments (47.5 dBA), when the occurrence frequency increases from 2 to 6 times, naturalness increases steadily from 4.7 to 6.4 , annoyance decreases slightly from 2.3 to 1.3 , and pleasantness increases significantly from 2.7 to 6.7 . The occurrence frequency of birdsong has a greater effect on pleasantness than naturalness and annoyance. When the traffic noise is noisy (62.5 $\mathrm{dBA})$, the occurrence frequency of birdsong has little influence on the masking effects. Visibility of sound sources influences the masking effects of birdsong, but this influence is not as great as that of the three other factors. It appears that the assessments of pleasantness (at 9, 19, and $50 \mathrm{~m}$ ) are more strongly affected by the visibility of sound sources, which may be attributed to the increased spatial awareness ${ }^{52}$ gained by adding visual information. The visibility of sound sources hardly affects masking in terms of perceived loudness, naturalness, and annoyance.

The relationships among the four soundscape characteristics were also examined by statistical analysis. For the soundscape dominated by road traffic noise investigated in this study, annoyance was determined to have a significant positive relationship with perceived loudness and a negative relationship with naturalness, whereas pleasantness was observed to have a significant negative relationship with perceived loudness and a positive relationship with naturalness. As stated by De Coensel et al., ${ }^{14}$ one possible explanation is that lower amount of attention paid to the traffic noise caused by adding natural sounds leads to a reduction of perceived loudness and significant improvement of soundscape pleasantness.

This study covered a relatively wide sound pressure level range of traffic noise, from 42.5 to $69.8 \mathrm{dBA}$, representing both noisy and quiet traffic noise environments. The recording distances ranged from 1 to $50 \mathrm{~m}$ from the main city roads. While the masking effects were more significant in the road traffic noise environments with lower sound levels (e.g., $<52.5 \mathrm{dBA}$ ), or of distance from traffic (e.g., $>19 \mathrm{~m}$ ), further study can be carried out with higher sound levels (e.g., highway), and/or shorter distance to traffic.

In accordance with the previous study, ${ }^{14}$ monaural recordings of birdsong were employed in the study, because the four factors that are the only variables in each comparable group should be examined in the controlled contexts. When compared with monaural recordings, binaural recordings include more uncontrolled spatial information (e.g., directions of high frequency sound-birdsong). Single recordings that were played back in the experiment had acceptable realism, which can be validated in the interview after the experiment. ${ }^{51}$ To do further study on the examination of influence of spatial information on the masking effects, binaural recording will be considered. Birdsong is effective at masking quiet traffic noise, so further studies will also investigate what sounds can more effectively mask loud traffic noise.

\section{ACKNOWLEDGMENTS}

This project is supported by the Northern Netherlands Provinces and funded by the European Union, European Fund for Regional Development and the Dutch Ministry of Economic Affairs, Peaks in the Delta.

${ }^{1}$ J. Y. Jeon, P. J. Lee, J. You, and J. Kang, "Perceptual assessment of quality of urban soundscapes with combined noise sources and water sounds," J. Acoust. Soc. Am. 127(3), 1357-1366 (2010).

${ }^{2}$ J. D. Krijnders, M. E. Niessen, and T. C. Andringa, "Sound event recognition through expectancy-based evaluation of signal-driven hypotheses," Pattern Recogn. Lett. 31(12), 1552-1559 (2010).

${ }^{3}$ C. Guastavino, "Categorization of environmental sounds," Can. J. Exp. Psychol. 61(1), 54-63 (2007).

${ }^{4}$ J. Kang, Urban Sound Environment (Taylor Francis, London, 2007), pp. 43-106.

${ }^{5}$ B. Schulte-Fortkamp and K. Voigt, "Why soundscape? The new approach to 'measure' quality of life," J. Acoust. Soc. Am. 131(4), Pt 2, 2434 (2012).

${ }^{6}$ A. L. Brown and A. Muhar, "An approach to the acoustic design of outdoor space,” J. Env. Planning Manage. 47(6), 827-842 (2004).

${ }^{7}$ D. Dubois, C. Guastavino, and M. Raimbault, "A cognitive approach to urban soundscapes: Using verbal data to access everyday life auditory categories," Acta Acust. Acust. 92(6), 865-874 (2006).

${ }^{8}$ C. Guastavino, "The ideal urban soundscape: Investigating the sound quality of French cities," Acta Acust. Acust. 92, 945-951(2006).

${ }^{9}$ A. Gidlöf-Gunnarsson and E. Öhrström, "Noise and well-being in urban residential environments: The potential role of perceived availability to nearby green areas," Landscape Urban Plan. 83(2-3), 115-126 (2007).

${ }^{10}$ V. Best, E. Ozmeral, F. J. Gallun, K. Sen, and B. G. Shinn-Cunningham, "Spatial unmasking of birdsong in human listeners: Energetic and informational factors," J. Acoust. Soc. Am. 118(6), 3766-3773 (2005).

${ }^{11}$ W. Halfwerk and H. Slabbekoorn, "A behavioural mechanism explaining noise-dependent frequency use in urban birdsong," Anim. Behav. 78(6), 1301-1307 (2009). 
${ }^{12}$ G. C. Cardoso and J. W. Atwell, "On the relation between loudness and the increased song frequency of urban birds," Anim. Behav. 82(4), 831-836 (2011).

${ }^{13}$ M. Rådsten-Ekman, Ö. Axelsson, and M. E. Nilsson, "Effects of sounds from water on perception of acoustic environments dominated by roadtraffic noise," Acta Acust. Acust. 99(2), 218-225 (2013).

${ }^{14}$ B. De Coensel, S. Vanwetswinkel, and D. Botteldooren, "Effects of natural sounds on the perception of road traffic noise," J. Acoust. Soc. Am. 129(4), EL148-EL153 (2011).

${ }^{15}$ Ö. Axelsson, M. E. Nilsson, B. Hellström, and P. Lundén, “A field experiment on the impact of sounds from a jet-and-basin fountain on soundscape quality in an urban park," Landsc. Urban Plan. 123, 49-60 (2014).

${ }^{16}$ R. Pheasant, K. Horoshenkov, G. Watts, and B. Barrett, "The acoustic and visual factors influencing the construction of tranquil space in urban and rural environments tranquil spaces-quiet places?," J. Acoust. Soc. Am. 123(3), 1446-1457 (2008).

${ }^{17}$ J. Y. Hong and J. Y. Jeon, "Designing sound and visual components for enhancement of urban soundscapes," J. Acoust. Soc. Am. 134(3), 2026-2036 (2013).

${ }^{18}$ L. Maffei, M. Masullo, F. Aletta, and M. Di Gabriele, "The influence of visual characteristics of barriers on railway noise perception," Sci. Total Environ. 445-446, 41-47 (2013).

${ }^{19}$ J. Liu, J. Kang, T. Luo, and H. Behm, "Landscape effects on soundscape experience in city parks," Sci. Total Environ. 454-455, 474-481 (2013).

${ }^{20}$ W. P. Tanner, "What is masking," J. Acoust. Soc. Am. 30, 919-921 (1958).

${ }^{21}$ B. C. J. Moore, "Mechanisms of masking," J. Acoust. Soc. Am. 57, 391-399 (1975).

${ }^{22}$ B. C. J. Moore, Hearing (Academic Press, New York, 1995), pp. 161-177.

${ }^{23}$ E. Zwicher and H. Fastl, Psychoacoustics-Facts and Models, 2nd ed. (Springer, New York, 1999), pp. 61-110.

${ }^{24}$ B. U. Seeber, "Masking and critical bands," in Handbook of Signal Processing in Acoustics, edited by D. Havelock, S. Kuwano, and M. Vorländer (Springer, New York, 2008), pp. 229-240.

${ }^{25}$ N. I. Durlach, "Auditory masking: Need for improved conceptual structure," J. Acoust. Soc. Am. 120, 1787-1790 (2006).

${ }^{26}$ G. Kidd, Jr., C. R. Mason, V. M. Richards, F. J. Gallun, and N. I. Durlach, "Informational masking," in Auditory Perception of Sound Sources, edited by W. A. Yost, R. F. Richard, and A. N. Popper (Springer, New York, 2008), pp. 143-189.

${ }^{27}$ N. I. Durlach, C. R. Mason, G. Kidd, Jr., T. L. Arbogast, H. S. Colburn, and B. G. Shinn-Cunningham, "Note on informational masking (L)," J. Acoust. Soc. Am. 113, 2984-2987 (2003).

${ }^{28}$ C. S. Watson, "Some comments on informational masking," Acta Acust. Acust. 91, 502-512 (2005)

${ }^{29}$ D. S. Brungart, B. D. Simpson, M. A. Ericson, and K. R. Scott, "Informational and energetic masking effects in the perception of multiple simultaneous talkers," J. Acoust. Soc. Am. 110, 2527-2538 (2001).

${ }^{30}$ T. L. Arbogast, C. R. Mason, and, G. Kidd, Jr., "The effect of spatial separation on informational and energetic masking of speech," J. Acoust. Soc. Am. 112(5), 2086-2098 (2002).

${ }^{31}$ W. A. Yost, "Perceiving sound sources," in Auditory Perception of Sound Source, edited by W. A. Yost, A. N. Popper, and R. R. Fay (Springer, New York, 2008), pp. 1-12.

${ }^{32}$ M. E. Nilsson, J. Alvarsson, and M. Rådsten-Ekman, "Loudness of fountain and road traffic sounds in a city park," in Proceedings of the 17th International Congress on Sound and Vibration, Krakow, Poland (2009), pp. 1-7.
${ }^{33}$ K. Bolin, M. E. Nilsson, and S. Khan, "The potential of natural sounds to mask wind turbine noise," Acta Acust. Acust. 96(1), 131-137 (2010).

${ }^{34}$ D. Raydan and K. Steemers, "Environmental urban design," in Environmental Design of Urban Buildings: An Integrated Approach, edited by M. Santamouris (Earthscan, London, 2006), pp. 1-35.

${ }^{35}$ J. M. McNamara, R. H. Mace, and A. I. Houston, "Optimal daily routines of singing and foraging in a bird singing to attract a mate," Behav. Ecol. Sociobiol. 20(6), 399-405 (1987).

${ }^{36} \mathrm{~B}$. Ambuel and S. A. Temple, "Area-dependent changes in the bird communities and vegetation of southern Wisconsin forests," Ecology 64(5), 1057-1068 (1983)

${ }^{37}$ G. S. Mills, J. B. Dunning, Jr., and J. M. Bates, "The relationship between breeding bird density and vegetation," Wilson Bull. 103(3), 468-479 (1991).

${ }^{38} \mathrm{~W}$. Yang and J. Kang, "Soundscapes and sound preferences in urban squares," J. Urban Des. 10(1), 61-80 (2005).

${ }^{39}$ Dateandtime.info, http://dateandtime.info/citysunrisesunset.php?id=27596 $33 \&$ month $=9 \&$ year $=2013$ (Last viewed 6/22/2012).

${ }^{40}$ T. Matsui, S. Furukawa, T. Takashima, I. Uchiyama, and K. Hiramtasu, "Time-component matrix chart as a tool for designing sonic environment having a diversity of sound sources," in Proceedings of Euronoise, Edinburgh, UK (2009), pp. 1-4.

${ }^{41}$ K. Hiramatsu, S. Furukawa, T. Matsui, and I. Uchiyama, "A physical expression of soundscape by means of Time Component Matrix Chart," in Proceedings of Inter-noise2008, Shanghai, China (2008).

${ }^{42} 5$ P. Clergeau, J. P. L. Savard, G. Mennechez, and G. Falardeau, "Bird abundance and diversity along an urban-rural gradient: A comparative study between two cities on different continents," Condor 100, 413-425 (1998).

${ }^{43}$ P. Clergeau, S. Croci, J. Jokimäki, M. L. Kaisanlahti-Jokimäki, and M. Dinetti, "Avifauna homogenisation by urbanisation: Analysis at different European latitudes," Biol. Conserv. 127(3), 336-344 (2006).

${ }^{44}$ J. Y. Jeon, P. J. Lee, and J. Y. Hong, "Non-auditory factors affecting urban soundscape evaluation,” J. Acoust. Soc. Am. 130(6), 3761-3770 (2011).

${ }^{45}$ K. Jambrošić, M. Horvat, and H. Domitrović, "Assessment of urban soundscapes with the focus on an architectural installation with musical features," J. Acoust. Soc. Am. 134, 869-879 (2013).

${ }^{46}$ G. Di, Q. Lin, and J. Kang, "Annoyance and activity disturbance from high-speed railway and conventional railway noise," Environmental Health 13(12), 1-10 (2014).

${ }^{47}$ D. Botteldooren, L. Dekoninck, and D. Gillis, "The influence of traffic noise on appreciation of the living quality of a neighbourhood," Int. J. Environ. Res. Public Health 8, 777-798 (2011).

${ }^{48}$ R. S. Ulrich, R. F. Simons, B. D. Losito, E. Fiorito, M. A. Miles, and M. Zelson, "Stress recovery during exposure to natural and urban environments,” J. Environ. Psychol. 11(3), 201-230 (1991).

${ }^{49} \mathrm{~S}$. Kaplan, "The restorative benefits of nature: Toward an integrative framework," Environ. Psychol. 15, 169-182 (1995).

${ }^{50}$ J. Liu and J. Kang, "Soundscape design in city parks: Exploring relationships between soundscape composition parameters and physical and psychoacoustic parameters," J. Envrion. Eng. Landscape Manag. 23, 110-120 (2015).

${ }^{51}$ Y. Hao, "Effects of urban morphology on urban sound environment from the perspective of masking effects," $\mathrm{Ph} . \mathrm{D}$. thesis, University of Sheffield, Sheffield, UK (2014), pp. 218-223.

${ }^{52}$ J. F. Augoyard and H. Torque, Sonic Experience: A Guide to Everyday Sounds (MacGill University Press, Montreal, 2005), pp. 19-152. 